\title{
Challenging the image of the altruistic and flexible household in the smart grid using design fiction
}

\author{
Sofie Nyström \\ Cecilia Katzeff \\ sofienys@kth.se \\ ckatzeff@kth.se \\ Department of Sustainable \\ Development, Environmental Science \\ and Engineering KTH Royal Institute \\ of Technology \\ Stockholm, Sweden
}

\author{
Miriam Börjesson Rivera \\ Arjun Rajendran Menon \\ miriamrg@kth.se \\ armenon@kth.se \\ Division of Media Technology and \\ Interaction Design KTH \\ Stockholm, Sweden
}

\author{
Björn Hedin \\ bjornh@kth.se \\ Department of Learning in \\ Engineering Sciences KTH \\ Stockholm, Sweden
}

\begin{abstract}
Power shortages and fluctuations in electricity supply are expected to become more frequent in the future, as renewable energy increases in the electricity mix. This poses a problem in that electricity might not always be available at the time of demand for industries as well as for households. Demand flexibility in households has been brought forward as part of a solution to this problem. How to engage households in this, however, is still unclear. Actors have tried to liken demand flexibility with waste sorting and other altruistic activities with connotations of contributing to the benefit of society, rather than being an activity springing from economic motives. In this article, we use design fiction to critically explore what this analogy would mean in the context of household electricity consumption. We describe fictive user scenarios for cooking, charging the electric car, laundry \& dishes and heating to draw the demand flexibility analogies to the forefront. By exemplifying and concretizing these scenarios, it becomes evident that using waste sorting as an analogy for demand flexibility is not realistic. We discuss the implications of the scenarios in relation to the current visions that inform the development of the smart grid, and the emerging services and service providers. We conclude that there is a need to challenge the current images of flexible households in the smart grid in order to design systems that support thriving within limits.
\end{abstract}

\section{KEYWORDS}

demand side response, smart grid, scenarios, flexibility, design fiction

\section{Reference Format:}

Sofie Nyström, Cecilia Katzeff, Miriam Börjesson Rivera, Arjun Rajendran Menon, and Björn Hedin. 2021. Challenging the image of the altruistic and flexible household in the smart grid using design fiction . In LIMITS '21: Workshop on Computing within Limits, fune 14-15, 2021.

Permission to make digital or hard copies of part or all of this work for personal or classroom use is granted without fee provided that copies are not made or distributed for profit or commercial advantage and that copies bear this notice and the full citation on the first page. Copyrights for third-party components of this work must be honored. For all other uses, contact the owner/author(s).

LIMITS '21, fune 14-15, 2021,

(C) 2021 Copyright held by the owner/author(s).

\section{INTRODUCTION}

The smart grid is part of the transition towards a more sustainable energy system, and as such interesting to discuss from a LIMITS perspective. The transition towards a more sustainable energy system rests on two major pillars: the electrification of society, and the transition towards integrating renewable energy sources into the electrical grid. The smart grid can thus be viewed as "a set of tools to balance and optimize the electricity grid, and to mitigate climate change" [15]. One of the characteristics of the smart grid is its capacity to encompass and distribute energy in 'both directions', thereby enabling prosumers and other microgrid-actors [15].

The smart grid is a response to the question of energy production and consumption that ideally rests upon renewable energy sources such as solar, wind and water. The main issue with an energy system relying on renewable energy sources is that many of the sources are intermittent and thus do not always meet the needs of the energy consumers. The sun might not be shining when households need electricity. Another issue which can lead to problems, is potential capacity deficits due to an undersized electricity grid. These two issues can separately, or together, create situations where electricity demand and supply do not match. Electricity demand may, for example, be heavy at times when the supply is low, due to weather conditions or the time of day. As a way to deal with this issue, the concepts of load balancing and demand-side response have been put forward by actors within the energy sector to denote an adaptation of the use of energy to its supply. This involves active participation of electricity consumers in the electricity system from industries as well as from private households. In residential buildings, peaks of electricity use occur mainly in the morning and in the evening, when people get ready for work and when they return home. Moving electricity-consuming activities to nonpeak hours is called peak shaving or load management and is generally considered one trend in the smart grid scenario.

Households have been pointed out as a key actor in demand flexibility in Sweden [1]. This is because the balance in the electric grid is becoming more dependent on the flexibility of households' electricity use along with the integration of renewables in the grid and with the strain on the grid capacity. Visions of households in the future electric grid, thus, include scenarios when householders shift their household chores to times of the day when this is optimal for the electricity grid. Strategies to meet the visions have 
been formulated on different levels in society and central questions circle around how electricity consumers may obtain relevant, easily accessible and comprehensible information about their electricity consumption and costs, which they may act upon. However, policy makers still struggle with how to motivate households in actually being flexible in their electricity use. There seems to be a lack of understanding the resistance to households engaging in load balancing. Although studies have indicated that people believe themselves to be quite flexible in their use of electricity, some activities might be non-negotiable in respect of the hours during the day they would be performed [23]. Shifting activities would involve a certain amount of planning and require information in advance about the periods of the day, during which they should avoid using electricity and how long that period would be.

In this paper we start out in an analogy that is frequently used in a Swedish smart grid setting, namely that load balancing should be "like source sorting your waste". In Sweden, households are responsible for separating and depositing their waste at available collection points, and to follow the municipality's rules for waste management. Property close collection system and bring/drop-off system are largely used to facilitate the collection and source separation. It is quite common that representatives for the energy sector and energy authorities compare the flexibility of electricity use with sorting waste in fractions, but are the activities involved in the two different practices really comparable? In the present paper, we challenge the relevance of the analogy and examine aspects characterizing each practice. The use of this type of comparison may actually cause more harm than benefit for the promotion as well as a fruitful discussion of flexible electricity use. Communicating this oversimplified analogy risks hiding the implications of load shifting and load balancing of electricity on households' everyday activities.

Both demand side response (DSR) and load balancing presuppose an active user. However, what exactly the "active user" does, or doesn't do, is ambiguous. On the one hand, the user should be active, aligning with the view of the consumer as being responsible for making informed decisions. This type of active user resembles the type of persona, referred to as 'Resource Man' [18]. This user ideal is described as a person, usually a male, who is interested in his own energy data, understands it, and makes changes in the way he uses energy based on this data. This idea of households as mini-energy managers has also been challenged from a design perspective [7]. On the other hand, the user is sometimes viewed as an obstacle [21] that in the best case needs to be informed, be made aware, and in the worst case, can be more or less bypassed by automated systems in place that steer both the timing and amount of electricity consumed.

From a LIMITS perspective load balancing and demand side response makes sense, as it in a tangible way emphasizes the limits of the energy system. However, what has not been fully investigated is how load balancing and demand flexibility is to be implemented in the smart grid and what role, if any, households will play. Visions that describe the role of households are ambiguous, fuzzy, and seldom explicit about what households are to do in practice.

Is the comparison of flexible electricity use in households with waste sorting really valid? What are the implications for household practices? In this paper we mean to untangle and thoroughly investigate some of these implications. We will do so by creating scenarios of everyday practices in the smart grid that build upon the assumptions. We will then critically discuss the scenarios, and what could be learned for future iterations/installations of the smart grid. We are focusing on the incentives and motivations used as arguments for demand side response by the energy industry rather than the enabling technology for DSR.

\section{RELATED WORK}

In this section, we describe the vision of the active user in a smart grid, how possible incentives have been used to motivate customers and the transition from treating end-users as customers to citizens.

\subsection{Rhetoric and visions in achieving active users in DSR}

In a study on user expectations in the smart grid Throndsen states that within the literature there were three main categories that the expectations fell into; "those of economic rationalization, technological bypass, or social science critique" [20, p.294]. Economic rationalization narratives means that the user's behavior depends purely on the costs of electricity and that "introducing different price regimes will trigger changes in behavior" [20, p.286], whereas technological bypass implies that the user is "imagined as behaving according to what the technology is supposed to do." [20, p.287]. The third narrative takes on a more critical stance and "provide[s] the most pessimistic view of the engaged smart grid consumer" [20, p.289], often in light of the economic and technological, which tend to be more positive. These strands of visions, or narratives, are loaded with expectations that in turn heavily influence how pilot projects and their results are understood. These three narratives also influence the rhetoric and visions of energy sector actors in a Swedish context. In a Swedish report "Smarta elnät - för vem?" (Smart grids - for whom?) [6] load balancing and the role that users should have in that is discussed. Actors state that even though load balancing is a key issue, the actual role that users should have may differ. For example, actors mention that the crucial point is "to raise awareness in order to be able to balance loads". Other actors mention "increasing energy awareness", "doing things differently" and "adopting the technology and understanding the context". There are however no concrete descriptions of how the smart grid would affect the everyday life of households. Representatives from the energy sector express themselves in an equally vague way in different sector specific media outlets but tend to stress that the contribution to the common good that the customer flexibility would lead to by likening electricity consumption awareness to sustainable habits like sorting your waste and buying organic food [4, 8]. By appealing to these types of norms, values and/or incentives the economic rationality is also bypassed, and the argument can thereby rely on notions of altruism.

\subsection{Motivating electricity load balancing for users}

"Everything rests upon voluntariness and that means that we have to create conditions so that it becomes easy for the customer to be flexible. And the incentives don't necessarily have to be economic, 
rather, it's just as important that customers feel that they are contributing to the common good. I usually compare it to how people sort their waste, there are other motivations than economic benefits behind that behavior." (Department manager at Swedish Energy Markets Inspectorate (authors' emphasis) [8])

"It's about achieving awareness about when it is best to use electricity, a bit like waste sorting, going by public transportation or buying organic food" (Head of Fortum SmartLiving at Fortum (authors' emphasis) [4])

Quotes like the ones above are perhaps at a first glance inconspicuous. By appealing to other incentives and motivations than the more common economic ones, actors within the energy sector try to circumvent the 'user as customer' and instead introduce the 'user as citizen', by recurrently comparing load balancing to waste sorting. The 'user as customer' has been how the user is envisioned and is still the most prevailing view among actors. Within the deregulated energy market, the 'user as customer' can complain if the services provided by the electricity company are not satisfactory and take their business elsewhere. The 'user as customer' compares prices and offers and chooses the most advantageous. However, the 'user as customer' has proven to be not quite so predictable as first assumed. Experiences from the first generation of smart meters and pilots with power tariffs have shown that users tend to not be quite so flexible when it comes to their electricity consumption $[10,16]$. This in turn has created a need for another narrative, and this is where the 'user as citizen' comes in. The 'user as customer' is aware, however, they are aware not (only) of prices but of other issues, such as sustainability. The 'user as citizen' is consequently assumed to feel a need to contribute in some way, based on this awareness, and thus expected to step up and assume some sort of responsibility. The proposal from actors is to usher the 'users as citizens' towards a role as a more flexible user that engages in load balancing. The role of 'user as citizen' implies that you should take responsibility both for the waste system (by sorting your waste) as well as for the energy system (by being a flexible electricity consumer). This way the users can make use of their awareness and willingness to contribute to the common good in a way that helps the energy system. However, load balancing and demand flexibility differ significantly from other more or less altruistic behaviors, such as waste sorting, buying biodynamic food and donating blood.

\subsection{Every small contribution matters all the time?}

For waste sorting, buying biodynamic food and donating blood it is usually clear for the individual that every single personal contribution matters and that actions by individuals are required. If you do not sort your waste it will likely end up in a landfill or be incinerated, if you do not buy biodynamic food you will buy non-biodynamic food instead with the consequences that follows, and if you do not donate blood someone else will have to donate instead. However, load balancing is not always relevant 24/7. Load balancing is most important at times when electricity production from intermittent sources is low and demand is high, such as cold winter days with no wind, but less important when intermittent electricity production is high and demand is low. This makes it difficult to have simple guidelines for load balancing that are easy for households to understand and follow. For waste sorting, a relevant guideline might be "it is always good to sort your waste" but for load balancing a similar guideline might be "it is often good to bake bread at $9 \mathrm{pm}$ rather than $5 \mathrm{pm}$ unless your energy mix includes large amounts of solar energy and the sun is shining. Then it is the other way around". Furthermore, load balancing is something that "can be solved by someone else", for example by your neighbor, the government, power companies or major industrial consumers of electricity.

\subsection{Active vs. passive choices}

Load balancing also differs from several other altruistic activities in terms of active vs passive choices. For waste sorting, there is always an active choice to either do "the right" action (sorting your waste) or "the wrong" action (throwing it in household waste). The consumer holding a used tin can in their hand has to make a choice to do either, there is no possibility to do neither, and continuous exposure to such choices makes it easier to internalize the behavior by making it a habit. For load balancing, the choices are more passive, where the default choice is business as usual ("make your cup of tea for breakfast", "run the dishwasher when it is full"), and the choice to actively engage in load balancing either has to be habitualized by integrated into daily routines (i.e. "stop drinking coffee for breakfast", "eat dinner later") or triggered by some external event ("This evening there will be electricity shortages, please don't use the oven").

\subsection{Homo economicus vs. Homo Altruisticus}

In economic theory, homo economicus is the traditional model of how people make decisions, being motivated by self-interest. Empirical evidence however has challenged this notion and has shown that many decisions are instead motivated by norms such as altruism, justice or social connectedness [14]. There are several studies [2, p.75-85] where the framing of a choice as either social/altruistic, or for money/personal benefit work in opposition, so that emphasizing personal economic benefits can make people less willing to engage in altruistic activities and vice versa. The arguments put forward by different actors for why to engage in load balancing are both for economic benefits ("save money if you charge your electric vehicle in the night") and for altruistic benefits ("by charging your electronic vehicle in the night you will support a renewable energy system"). Waste sorting on the other hand is mainly altruistic, thereby making the argument and underlying motivation much clearer.

\section{DESIGN FICTION SCENARIOS}

The general assumption or "vision" is that households and customers should "adapt" and be flexible in the smart grid. There are however very few examples (as shown in the quotes above) of which actions that end-users are expected to carry out. To stimulate a further discussion of this, we flesh out possible behaviors in the shape of scenarios. The scenario approach is inspired by design fiction [22] as we see the power in this approach to reveal how future technology would affect everyday life. The purpose of the scenarios is to illustrate what it would mean for households to be flexible if flexible electricity use were to be treated in the same way 
as for example waste sorting. As a consequence, the spirit of the scenarios will be consciously framed as positive and adaptable. Our different scenarios are based on some core aspects or dimensions for end-user flexibility. The specific dimensions are selected because of their essential impact on household decisions and practices. The following dimensions are used for the scenarios:

- Manual control vs. automatic

- Manual control is when actions or decisions are made by the household or individuals themselves. They can get reminders, triggers or notifications to do so, but are ultimately responsible themselves for their decisions.

- Automatic control is when decisions are made by an external actor who is in control of one or more household appliances. This could be either an aggregator or an automatic system of some kind.

- Frequency of behavior

- Everyday behavior or actions, for example shifting electricity usage during peak hours 7-9 and 17-19.

- Seldom behavior that needs measures out of the ordinary, such as cold weather with no wind when energy production is low (could go on for weeks). Peak hours during these periods would be even more critical as electricity prices then are expected to be very high.

To facilitate the creation of scenarios, we created a two-dimensional matrix with the dimensions above (see Figure 1). In our scenarios, we explore contexts where households adapt their electricity use to relieve the strain on the grid. The scenarios circle around four electricity using activities, especially selected because of their relevance for everyday life. Cooking, laundry and dishes form part of normal household chores and relate to needs of food and cleanliness. Heating is selected because of its central role for people to keep warm in the buildings where they live and because heat pumps are a central technology appearing in discussions on the role of technology in load balancing. Finally, the charging of electric vehicles is chosen not because this will be included in all households, but because it also plays a central role for balancing the electricity load.

\subsection{Automatic and seldom}

This category describes scenarios of household activities using appliances being controlled automatically and seldomly.

3.1.1 Design Fiction: Cooking. "Honey, I got a notification now saying that because of the cold weather, the freezer will be out of power until midnight."

- What, but I am on my way to the supermarket for the weekly shopping!

- I know. Perhaps it will still be OK as the temperature stays roughly the same if we don't open the freezer door too much.

- Sigh, I guess so.

A couple of times per year, the freezer can be automatically controlled to be turned off during certain hours and cold weather. At first, they thought this was really obtrusive and scary that the freezer would be turned off. But they are now used to it, and this happens to everyone. It feels good also to contribute to a more sustainable use of resources.

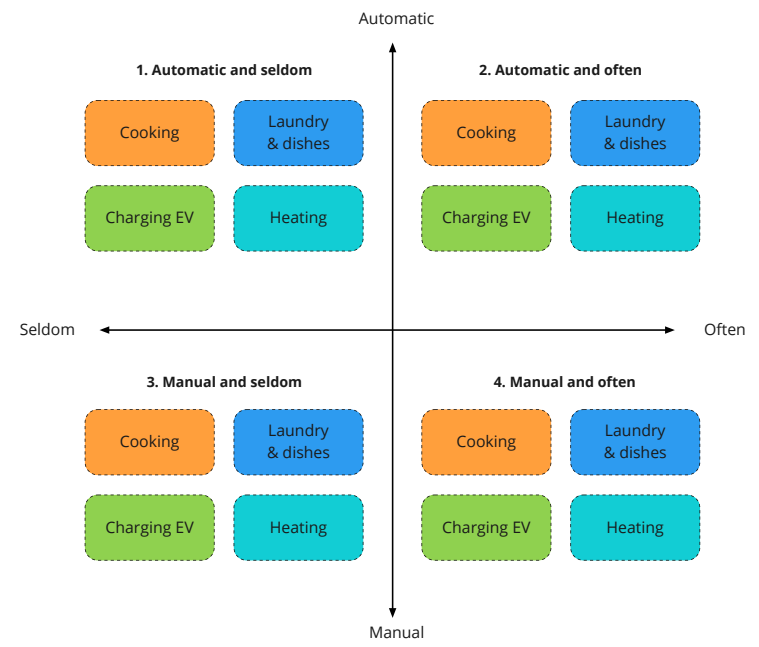

Figure 1: Image of the different practices along the axes for the dimensions Manual vs. Automatic and Frequency of behavior.

3.1.2 Design fiction: Charging EV. Steven and Ella have an electric car. It's great and so silent, and they can control when it should be charged through an app. "It is very convenient!" Steven says.

But a few times each year, the car won't charge immediately when it is plugged in like it usually does. Ella then gets a notification saying that the charging of the car is delayed until after midnight. In most cases when they would not be taking the car until the next day, the delay doesn't matter. But one time, they had dinner plans with a friend living an hour away, and they didn't dare to take the car because it wouldn't charge.

"It was probably a one time thing though. Now we have also learned how much the car can charge and how you should drive to have the battery last longer" Ella says.

3.1.3 Design fiction: Heating. "Tomorrow, between 12:00 and 18:00, the heat will be switched off every two hours due to reduced electricity production", read the notification. "Wow!", Elias thought. "It's showtime!" Now he could finally get to test how the house kept warm if the heat pump was turned off every two hours. "What would it look like on the electricity bill?", Elias wondered. If the temperature did not fall too much, maybe they could talk to their aggregator and continue scheduling something like this? "I wonder how much we could save then?" Elias continued to ponder. And if it got cold, they could always light a fire in their fireplace or even bring out the gas stove. Elias had put much thought into how he would adapt to a crisis situation, and saw this as a golden opportunity to test his equipment!

3.1.4 Design fiction: Laundry and dishes. In Bert's housing association, the dryer in the common laundry room is automatically turned off during cold periods in the winter. It usually lasts for a week or two, at most. Bert is on the board and was part of the decision to install an automatic plug that turns off the dryer. In that 
way, they can lower their electricity bill and also contribute to the electricity balance. "We hang our laundry in the apartment instead. It's also good because the wet clothes bring up the humidity!"

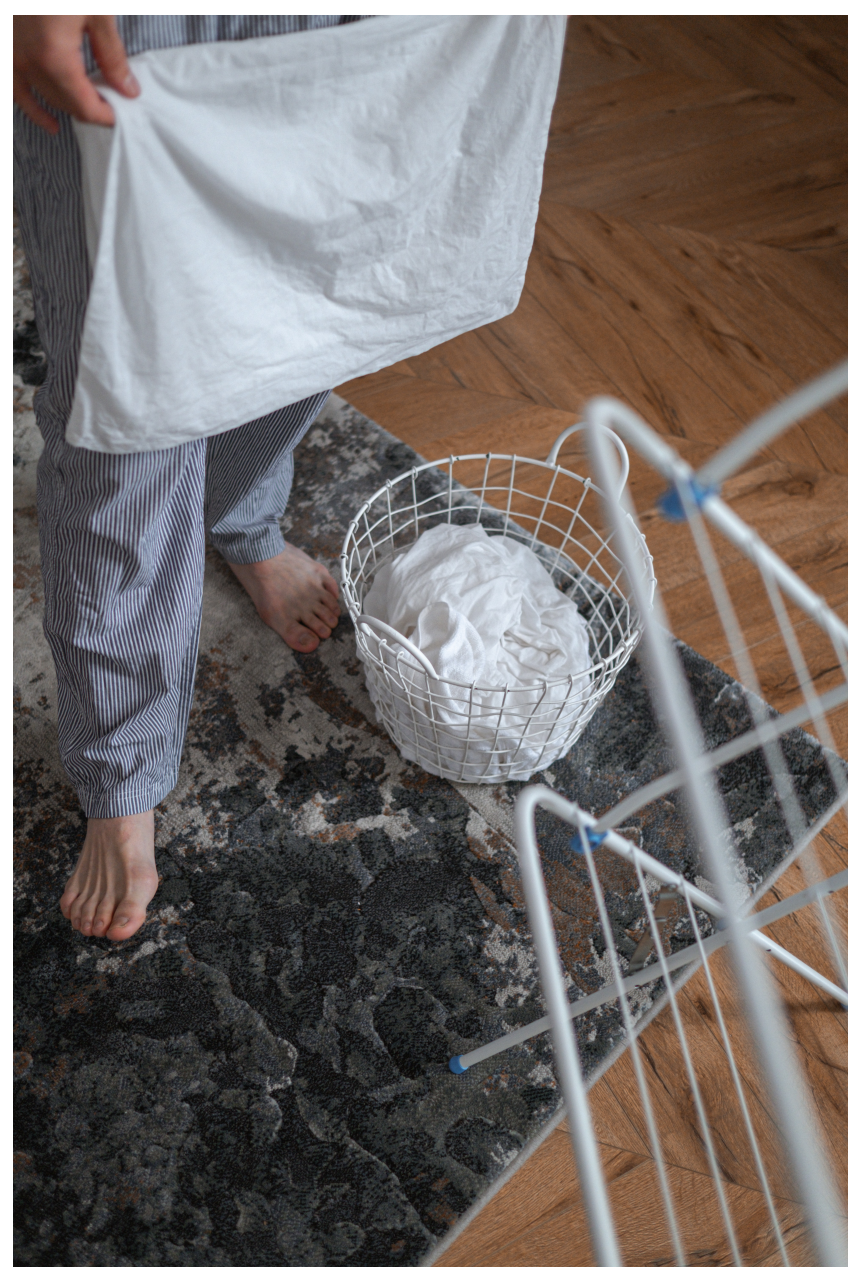

Figure 2: Hanging laundry to dry in the apartment. Photograph by cottonbro via Pexels, (https://bit.ly/3fdGiic).

The scenarios in the Automatic and seldom category are rare events that happen because of lack of electricity production or cold periods. From the scenarios, we may conclude that households do not need to carry out any deliberate actions, as the load balancing is forced upon the users by an external actor. Households are therefore bypassed and simply need to adapt to the flexibility measures. Users described in the scenarios are positive to the flexibility measurements although it can be an obstacle for everyday practices, simply because they know they are contributing and are doing it for the common good.

\subsection{Automatic and often}

This category describes scenarios of household activities using appliances being controlled automatically and often.
3.2.1 Design fiction: Cooking. The fridge power is varying according to the electricity grid, meaning that it is not turned on during 7-9 or 17-19. Ruth, 56 says: "At first we were worried, what if it affects the food to rot more easily? And especially during those warm summer months when food tends to go bad. But we haven't given it much thought actually, and have not noticed any difference in the temperature. We try to not put in a lot of stuff during those hours, for example to let any leftovers reach room temperature before putting it in the fridge. We also rearranged our weekly shopping routine to 9AM at Saturdays instead of 5PM on Thursdays. You know, to ease the strain on the fridge."

3.2.2 Design fiction: Charging EV. - Mom! Why won't the car charge? shouts Liza from the garage.

- It's past 5 ! It never charges between 5 and 7 ! mom replies from the living room. Leave it plugged in, and the charging will start again at 7 .

The family Prius is used a lot, driving the kids to school and sports activities, and now their oldest just got her driver's license too. But the family is not the only ones who are using the car. It is also controlled automatically to not be charged during peak hours, in order to reduce the strain on the grid. The policy is something they had to agree on when buying the car. When reading about this policy initially, they almost gave up the idea of the electric car because they thought it would be too insecure. But now, they have gotten used to the fact that the car is not charged between 5 and 7 $\mathrm{pm}$. As long as they make sure the battery has enough power when the time starts, it's not an issue.

3.2.3 Design fiction: Heating. At the Johnson's, environmental issues have always been very important. A year ago, they agreed to an offer by the municipal energy company to help balance the grid and even out the peaks. In this way, electricity use becomes more sustainable and you do not have to start coal or oil power plants. And at the Johnson house, it is not even noticeable that their heat pump is controlled by the energy company and that it is turned off during the peaks between 07:00 - 09:00 and between 17:00 - 19:00. "It feels like a win-win situation for everyone!" they say.

3.2.4 Design fiction: Laundry and dishes. In a family of four, the laundry quickly piles up. Marcus bought a smart washing machine when the old one broke down. The new one is more energy efficient but can also be scheduled to start when the electricity fee is low. Marcus loves that functionality. And then he can hang the clothes in the morning instead of staying up late to hang the clothes before bedtime. Marcus can also start the washing machine remotely from an app when he knows he will be home in a couple of hours. "But it's still best to run it in the night when the price is low, that way you can take advantage of electricity that otherwise might not get used."

In the second category for automatic and often, scenarios show that new technology and automation control appliances almost every day by shifting its electricity usage to outside of peak hours. The scenarios highlight situations when the impact on everyday activities is quite small in the heat pump scenario. However, they also highlight situations where the impact on everyday activities is quite large as in the scenario of charging the electric vehicle. The 
enabler for remotely controlling electricity use can be implemented as a requirement or installed by the households themselves.

\subsection{Manual and seldom}

This category describes scenarios of household activities using appliances being controlled manually by individuals themselves and seldom.

3.3.1 Design fiction: Cooking. During extreme weather, for example really cold periods with no wind, the app from their aggregator Aggry notifies the family that measures are needed. It suggests that the oven or stove should not be used tonight, and suggests ordering food from the local pizza place instead. It will also suggest that the heating pump is to be turned off during the evening "The kids love those occasions, and the pizza makes up for the cooler temperature indoors" says Robert, 47.

3.3.2 Design fiction: Charging EV. Regina, 68, looks at the weather forecast on Monday evening, notices that it will be -10 degrees Celsius for the next couple of days and also that the wind will not blow more than $5 \mathrm{~m} / \mathrm{s}$. "It is probably best not to charge the electric car during the day", she reasons. She and her husband, Elof, are retired and mostly stay at home. Perhaps it will be enough to charge the electric car at night, she reasons. Regina goes out in the evening to the garage and plugs in the electric car. The first thing she does in the morning after getting up at $6 \mathrm{AM}$ is to unplug the cord; the car is fully charged anyway. They have not planned to go anywhere either today or tomorrow, so it does not matter much. On Wednesday evening, Regina goes out and plugs in the cord to the electric car again. Tomorrow, it will be warmer and the forecast no longer warns of electricity shortages. It suits Regina well because she needs to drive Elof to the podiatrist tomorrow and the car needs to be fully charged for their trip.

3.3.3 Design fiction: Heating. Ann is not so interested in smart technology. She does not want to be surrounded by so many technical gadgets that do things without her knowing about it, and having to share her data with someone else. She has heard of neighbors who have connected their heat pump to be controlled according to how much electricity there is in the grid, but she has come up with her own solution. When the temperature drops below -5 degrees Celsius, she goes down in the basement herself and switches off the heat pump in the mornings, switches it on in the middle of the day, switches it off before dinner and switches it on again before going to bed. This way, she feels involved and contributing to the electricity network without being stressed. Sure, it might get a little colder during those days, but then she just puts on an extra sweater and her comfortable wool slippers.

3.3.4 Design fiction: Laundry and dishes. "Today is cold and very little wind. It is not a good day to do laundry" read the notification from the aggregator.

- Shoot, Albert thought. I should have seen that coming when I saw the forecast. Maybe I can turn on the machine late tonight and hang it really early tomorrow. That will have to do. I hope my daughter won't be too mad that her favorite sweater won't be clean and dry for her school photography session tomorrow.
In the manual and seldom category, measurements are needed from the household themselves in response to quite rare events, such as cold periods when electricity production is low. Although they are sometimes reminded to be flexible, it is very much up to the individuals to act upon them. From the scenarios we can conclude that these disruptive moments demand quite a lot from the flexible households, for example adjusting the heating several times per day or changing cooking routines. These events do also have a quite high impact on households' everyday life as they need to renegotiate and plan around these extraordinary events.

\subsection{Manual and often}

This category describes scenarios of household activities using appliances being controlled manually by individuals themselves and often.

3.4.1 Design fiction: Cooking. When Philip gets home around 16.30 each day, he usually starts with dinner directly. That way, he avoids using the oven between 17-18 when there is a high strain on the regional grid. Sometimes, when he and his daughter have soccer practice in the evenings, they need to have an early dinner. In that case, he can either leave work a bit earlier to start dinner, or cook something that doesn't require the oven, like pasta or heat-up leftovers. And on weekends, they can be a bit more flexible.

3.4.2 Design fiction: Charging EV. Rufus has an electric hybrid that he is very happy with. He travels mostly short distances and since the car also charges when he brakes, he thinks that the battery lasts a long time. In the evenings when he walks the dog, he always makes sure to plug the cord in the car. In the same way, the morning walk always starts with Rufus unplugging the car. This way, he ensures that the battery does not need to be charged during the day when the electricity price is higher. It is not so much about that it is better for the wallet to charge at night, it is also about not being an unnecessary burden when he might as well charge the car during the night instead.

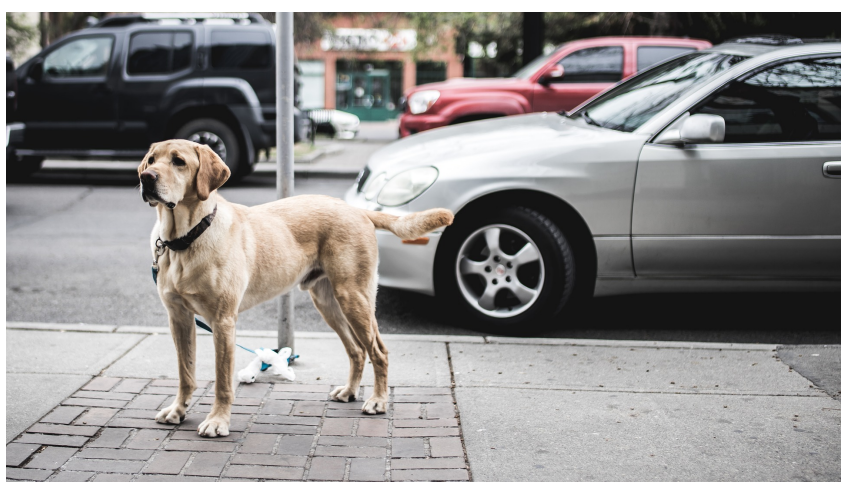

Figure 3: A dog waiting in front of a car. Photograph via Pixabay (https://bit.ly/3fJxUpt).

3.4.3 Design fiction: Heating. Peter is 64 and lives in a suburb outside of Stockholm. As a part of his daily routines, Peter turns down the heat on the radiators early in the morning and in the late afternoon, to ease the strain on the grid during peak hours. It's 
just something one should do, to not be reckless with electricity, he argues. "I thought everyone living in a house with controllable heating did this?"

3.4.4 Design fiction: Laundry and dishes. In the Robertson family, routines and planning is essential. Dinner is usually around 6.30, homework is to be done after and sports activities before. The dishwasher is loaded after dinner, but not turned on until after 9 .

- We don't want to put unnecessary pressure on the grid, since it doesn't really matter when the dishes are done. Dad is usually awake quite late and empties the dishwasher before bedtime.

In the manual and often type scenarios, households need to manually adapt their use of appliances almost everyday to be flexible in their electricity consumption. Most households in this category have incorporated flexibility into their everyday routines like walking the dog. These types of measurements require a lot of effort from the households in terms of manual planning and control and can be expected to have a considerable impact on their everyday life.

\subsection{General conclusions from scenarios}

This analogy of households' flexible electricity use as waste sorting contains several, sometimes contradictory, implications. General conclusions from the scenarios described above highlight and concretize these discrepancies. In general, households are not being flexible for economic reasons as it is more about contributing to the common good and acting upon a general awareness of when it is appropriate or not to consume energy. What is happening in the scenarios is that users do one of four things: 1) they are being bypassed by automation that "takes care" of the flexibility measures without the people noticing, 2) they need to adapt to decisions made by an external agent such as controlling appliances, 3) they experience disruptive events that demand them to use electricity differently or 4) they have become used to peak hours and have made sacrifices or changes to their everyday routines that involve shifted use of electricity. Common for all scenarios is the positive attitude and that users are willing to adapt and comply with load balancing measures, something that is unlikely to happen in reality.

\section{DISCUSSION}

The scenarios presented above are idealistic scenarios, rather than realistic ones. The scenarios are based on the different altruistic connotations underpinning the visions and expectations of an activity such as waste sorting, and thus deliberately written in a positive and optimistic way. As illustrated by the scenarios, altering important practices manually (such as preparing food) or too often (turning on heat pump three times per day) will seem unrealistic to most, especially if the main incentive is supposedly altruistic. Traditionally, economic incentives have been a central motivator for behavior changes within the energy sector, and are still mainly used as an argument for shifting electricity use. This, in combination with the ambiguity with altruistic incentives and the possible distrust and skepticism towards electricity companies [17] makes the challenge of demand-side flexibility even more complicated. The altruistic aspect is also emphasized in the scenarios as "easing the strain on the grid" or "avoiding putting unnecessary pressure on the grid" which is far from the reliable and stable network that most countries are currently used to.

\subsection{Who has flexibility capital?}

The scenarios described are ranging from highly automated and out of the users' control, to highly manual, where all responsibility lies on the individuals. However, what all scenarios assume is that there is always an ability or capacity to be responsive and flexible. The scenarios were also deliberately describing households of a certain socio-economic group that has economic and social capacity to engage in demand-side flexibility. This capacity of being flexible is not equally distributed among households, and it is therefore not realistic to expect similar flexibility from all types of households $[3,12]$. Flexibility capital is restricted socially, technically and economically and it is therefore problematic to expect users to simply be flexible based on altruistic assumptions. To be flexible, households will need a ranging amount of knowledge, time and equipment (and therefore also economy). Households with more electrical appliances that potentially can cause strain on the grid are also more interesting to control from a grid point-of-view, where for example apartments often are regarded as too small to make a difference. In addition, the capacity for being flexible is limited in terms of societal structure. Our electricity usage and everyday social practices are highly dependent on when we are at home before and after school or work, resulting in peaks of electricity use [19]. The "capacity" to be flexible is therefore highly restricted to societal structures and expectations that are beyond the control of the individual. As the scenarios show, there is not much or any thought given to households with a more limited economy, which in turn opens up for e.g. energy poverty potentially becoming a concern in the future.

\subsection{Who has control to be flexible?}

As seen in the scenario with automating the heat pump performance, some technology can be controlled by an external actor or automatic system without users being aware of it. These types of actions are often mentioned as an easy and convenient development of demand-side response, to hand over the control to another agent, either to an external actor or to 'smart' technology. This has been argued as a possibility for demand-flexibility that allows for aggregation, and thus can become aggregated and controlled without depending on human interference. Furthermore, this is argued to relieve the flexibility burden of the households as the technology can be automatically flexible for them. Users are encouraged to install "smart" controllable appliances that can be controlled by an external actor, that in turn allow for new types of actors on the energy market, e.g. aggregators. This development triggers a whole new set of issues and questions related to control (or lack thereof), transparency, trust, overriding, privacy and data ownership. It is essential that all of these aspects are addressed within demand-side flexibility to allow for a more open and decentralized energy system where the messiness of everyday life and practices are treated respectfully.

In line with a democratic societal development, the transition towards a sustainable energy system needs to be a just and inclusive one. This means, among other things, that underlying assumptions 
that inform the current visions and expectations on the role of e.g. households need to be challenged and replaced. As discussed, it is difficult to lean too much upon altruistic notions if there is no sense of actual participation, or reciprocity. There is a risk that an energy system built upon this 'false' sense of participation might exacerbate the already existing lack of trust towards actors in the energy system. The way that the smart grid is envisioned today, the role afforded to the households is fundamentally one as an individual measuring point among millions of others. At the same time, rather than "just" allowing customers to evolve from consumers to prosumers, the smart grid could theoretically allow for minor actors, such as households taking a bigger responsibility, through e.g. load balancing. The benefits however, need to be more meaningful than the currently proposed fuzzy contributions to the common good. One way to do so could be by making way for open, decentralized and more local energy communities, where the energy and/or capacity produced is consumed primarily by the producers themselves in the vicinity. This would also lead to a reframing of the households from 'users' and into actual energy citizens rather than the cosmetic change from 'user as customer' to 'user as citizen' described in 2.2 .

This reframing of household's role in the energy system could help foster another, perhaps deeper, relationship with electricity, than the current and proposed system does. A relationship where the ebbs and flows of renewable electricity production are matched by changes in social practices. This would require that we question the supply of energy as stable and always accessible, in order to comply with intermittent energy production. A deeper relationship with energy could however be beneficent both for understanding local supply and demand of energy as well as improving the relationship between actors on the energy market. An initial step towards this is the new energy citizen communities directive introduced in the EU package "Clean Energy for all Europeans" (https://op.europa.eu/s/pcrQ). In addition, overall societal temporal schemes would need to be altered, in order to allow people that currently don't have the flexibility capital to partake in the load balancing. Certain causes for the need of load balancing would thus be mitigated, if not removed.

\subsection{Demand-side response within LIMITS}

From a LIMITS perspective everyday life in the smart grid is interesting for many reasons. To begin with, moving away from the dependence of fossil fuels is crucial, both in terms of climate crisis and considering that fossil fuels are finite resources [13]. However, the question of "how renewable energy sources will be able to meet an increasing energy demand" (ibid., Author's emphasis) is still open for discussion. Hilty [5] discusses how flexibilizing energy demand could look like and states that it may require a change of social practices. Moreover, he speculates that this adaptation towards the pace of the renewable energy supply could lead to socio-technical innovation (ibid.). This line of reasoning in some ways also echoes what Pargman et al. [11] envision "using stores of energy, and making the most of energy as a limited resource when it is available (and being robust to when it isn't) will be a new paradigm". Neither can however, in detail convey what everyday life in such a future could look like. Finally, delving into scenarios of everyday life makes sense from what Mann et al. [9] propose in their vision for regenerative LIMITS, namely, that we need to "develop a clear vision of what a viable alternative might look like". Scenarios, such as the ones described in this paper can also be viewed as "narratives and stories of technology and computing that are more closely intertwined with nature" that at the same time show how they "fit into and contribute to wider systems" [9]. The scenarios in this paper, while based on the visions propagated by actors within the energy sector as well as in policy, reveal implications that may or may not be desired. Nevertheless, we argue that narratives and stories of technology, such as these scenarios, are necessary to explore and discuss to eventually be able to design systems that truly allow "thriving within limits" [9].

\section{CONCLUSIONS}

We have critically analyzed the idea of households as contributors to the smart grid through load balancing using incentives such as general awareness and waste sorting similarities. This idea suggests that the role of households would transition from the traditional passive customer to a more flexible role where individuals take part in the electricity system as a citizen. By illustrating what flexibility measures that householders might face in this transition through scenarios from design fiction, we uncover the uncertainty and vagueness of this analogy. We conclude that households and users in the energy system need to be democratically and inclusively involved in the energy transition, and current visions of the users as altruistically engaged need to be challenged. We encourage that users are allowed to truly become active participants through a stronger relationship to electricity produced locally and that the benefits of being an active participant are more clearly defined and communicated.

\section{ACKNOWLEDGEMENTS}

This study was possible through a grant from the Swedish Energy Agency and the project Smart grid stories from the home and participation in future electricity systems (49533-1).

\section{REFERENCES}

[1] Karin Alvehag and Linda m.fl Werther Öhling. 2016. Åtgärder För Ökad Efterfrågeflexibilitet I Det Svenska Elsystemet. Energimarknadsinspektionen (2016). https://www.ei.se/Documents/Publikationer/rapporter_och_pm/ Rapporter2016/Ei_R2016_15.pdf

[2] Dan Ariely. 2010. Predictably irrational : the hidden forces that shape our decisions. First Harper Perennial edition. New York : Harper Perennial, 2010. https://search. library.wisc.edu/catalog/9910058737002121

[3] Ingvild Firman Fjellså, Antti Silvast, and Tomas Moe Skjølsvold. 2021. Justice aspects of flexible household electricity consumption in future smart energy systems. Environmental Innovation and Societal Transitions 38, December 2020 (2021), 98-109. https://doi.org/10.1016/j.eist.2020.11.002

[4] Per Henricsson. 2015. Så blir Sverige bäst på smarta elnät. https://etn.se/index. $\mathrm{php} / 61549$

[5] Lorenz Hilty. 2015. Computing Efficiency, Sufficiency, and Self-sufficiency: A Model for Sustainability? Limits 2015 June (2015).

[6] Cecilia Katzeff, Hanna Hasselqvist, Elin Önnevall, and Sofie Nyström. 2018. Smarta elnät - För vem? Óversikt och analys av användaraspekter på smarta elnät för bostäder. Technical Report. E2B2, Stockholm. http://www.e2b2.se/ forskningsprojekt-i-e2b2/beteende/smarta-elnaet-foer-vem/

[7] Cecilia Katzeff, Stina Wessman, and Sara Colombo. 2017. "Mama, It's Peacetime!": Planning, Shifting, and Designing Activities in the Smart Grid Scenario. In Proceedings of the Conference on Design and Semantics of Form and Movement - Sense and Sensitivity, DeSForM, 2017. 133-147. https://doi.org/10.5772/46845

[8] Daniel Löfstedt. 2017. Småhus viktigast för efterfrågeflexibilitet. https://secondopinion.se/smahus-viktigast-efterfrageflexibilitet/ 
[9] Samuel Mann, Oliver Bates, Glenys Forsyth, and Phil Osborne. 2018. Regenerative computing: De-limiting hope. ACM International Conference Proceeding Series (2018). https://doi.org/10.1145/3232617.3232618

[10] Isak Öhrlund, Åse Linné, and Cajsa Bartusch. 2019. Convenience before coins: Household responses to dual dynamic price signals and energy feedback in Sweden. Energy Research \& Social Science 52, July 2018 (jun 2019), 236-246. https://doi.org/10.1016/j.erss.2019.02.008

[11] Daniel Pargman, Elina Eriksson, and Adrian Friday. 2016. Limits to the sharing economy. ACM International Conference Proceeding Series (2016). https://doi. org/10.1145/2926676.2926683

[12] Gareth Powells and Michael J. Fell. 2019. Flexibility capital and flexibility justice in smart energy systems. Energy Research \& Social Science 54 (aug 2019), 56-59. https://doi.org/10.1016/j.erss.2019.03.015

[13] Tina Ringenson, Elina Eriksson, Miriam Börjesson Rivera, and Josefin Wangel. 2017. The Limits of the Smart Sustainable City. In Proceedings of the 2017 Workshop on Computing Within Limits. ACM, New York, NY, USA, 3-9. https://doi.org/10. 1145/3080556.3080559

[14] Shalom Schwartz. 1975. The Justice of Need and the Activation of Humanitarian Norms. Journal of social issues 31, 3 (1975), 111-136.

[15] Tomas Moe Skjølsvold, Marianne Ryghaug, and Thomas Berker. 2015. A traveler's guide to smart grids and the social sciences. Energy Research \& Social Science 9 (sep 2015), 1-8. https://doi.org/10.1016/j.erss.2015.08.017

[16] Robin Smale, Bas van Vliet, and Gert Spaargaren. 2017. When social practices meet smart grids: Flexibility, grid management, and domestic consumption in The Netherlands. Energy Research \& Social Science 34, February (dec 2017), 132-140. https://doi.org/10.1016/j.erss.2017.06.037

[17] Karen Stenner, Elisha R. Frederiks, Elizabeth V. Hobman, and Stephanie Cook. 2017. Willingness to participate in direct load control: The role of consumer distrust. Applied Energy 189 (mar 2017), 76-88. https://doi.org/10.1016/j.apenergy. 2016.10.099

[18] Yolande Strengers. 2014. Smart energy in everyday life: are you designing for resource man? Interactions 21, 4 (2014), 24-31. https://doi.org/10.1145/2621931

[19] Yolande Strengers, Larissa Nicholls, and Cecily Maller. 2016. Curious energy consumers: Humans and nonhumans in assemblages of household practice. fournal of Consumer Culture 16, 3 (nov 2016), 761-780. https://doi.org/10.1177/ 1469540514536194

[20] William Throndsen. 2017. What do experts talk about when they talk about users? Expectations and imagined users in the smart grid. Energy Efficiency 10, 2 (2017), 283-297. https://doi.org/10.1007/s12053-016-9456-5

[21] Geert P J Verbong, Sjouke Beemsterboer, and Frans Sengers. 2013. Smart grids or smart users? Involving users in developing a low carbon electricity economy. Energy Policy 52 (2013), 117-125. https://doi.org/10.1016/j.enpol.2012.05.003 arXiv:arXiv:1011.1669v3

[22] Ron Wakkary, Audrey Desjardins, Sabrina Hauser, and Leah Maestri. 2013. A sustainable design fiction: Green practices. ACM Transactions on ComputerHuman Interaction 20, 4 (2013), 1-34. https://doi.org/10.1145/2494265

[23] Stina Wessman. 2016. PLEASE MIND THE BALANCE. USING DESIGN TO ENGAGE HOUSEHOLDS IN THE SMART GRID SCENARIO. In 11th EAD Conference Proceedings: The Value of Design Research. Sheffield Hallam University. https://doi.org/10.7190/ead/2015/174 